\title{
HOW TO USE THE DHT22 SENSOR FOR MEASURING TEMPERATURE AND HUMIDITY WITH THE ARDUINO BOARD
}

\author{
BOGDAN Mihai \\ Associate professor, Ph.D, Faculty of Engineering, Computer Science and Electrical Engineering \\ Department, ”Lucian Blaga”University of Sibiu, Romania, mihai.bogdan@ulbsibiu.ro
}

\begin{abstract}
The objective of this paper is to achieve a functional system in terms of hardware and software, to measure temperature and humidity. Also, this system will allow to monitoring the time. In this, we use an Arduino board with interfacing a sensor placed in local environment to measure temperature and humidity. The paper aims to achieve the following goals:

- achieving a functional system in terms of hardware and software that allows measuring and monitoring temperature, humidity and the time;

- using a development board for the communication with the sensor and clock;

- implementation a program that allows requirements.
\end{abstract}

Key words: Arduino, Integrated Development Environment, DHT22 sensor, Real Time Clock, MaxDetect 1wire

\section{Introduction}

There heating systems that require special attention, especially in winter, when it is necessary to be constant temperature and humidity to have a desired comfort. With a data acquisition board can achieve a system that will allow monitoring temperature and humidity in a room. I used as data acquisition board, an Arduino board. Using an Arduino data acquisition board has the following advantages [4]:

- is open source;

- is easily programmed;

- can be used on any operating system;

- low cost.

Arduino boards can be programmed easily using the Integrated Development Environment (IDE ). This environment is for writing programs that can be loaded on the board [3]. Arduino is found in several variants depending on the sizes and capabilities. The board used for this work is Arduino Uno. The difference between Arduino Uno and other boards is that this board does not use a driver FTDI USB to serial chip, but uses ATmega16U2 microcontroller that is programmed as a USB to serial converter.

Measurement and maintaining constant temperature is important in industrial processes. Temperature transducers which are used in electrical measurements are numerous due to a wide range of temperature being measured, and because of the measurement accuracy in a specific area.

Humidity is the amount of water vapor which is contained in a sample of air. It is a very important feature of the air both in terms of weather as well as in terms of bioclimatic. Solids and liquids humidity measurement is done using umidimetrelor. They express the water content that is found in materials. In the expression of the humidity, enter the wet material mass and the dry material mass.

Humidity is expressed as follows:

- absolute humidity:

$$
U_{a}=\frac{m_{h}-m_{u}}{m_{u}} 100[\%]
$$

- relative humidity :

$$
U_{r}=\frac{m_{h}-m_{u}}{m_{h}} 100 \text { [\%] }
$$

Humidity measurement is based on the change of physical properties due to moisture. Moisture measurement methods are based on variation in resistivity, variation of capacity or the variation in the degree of attenuation of microwaves. 


\section{The block diagram of the system}

Represented in Figure 1 is a block diagram of the measuring system. It contains the following functional blocks: $5 \mathrm{~V}$ source, 7-12 V input voltage, Arduino board, temperature and humidity sensor, RTC, battery and LCD.

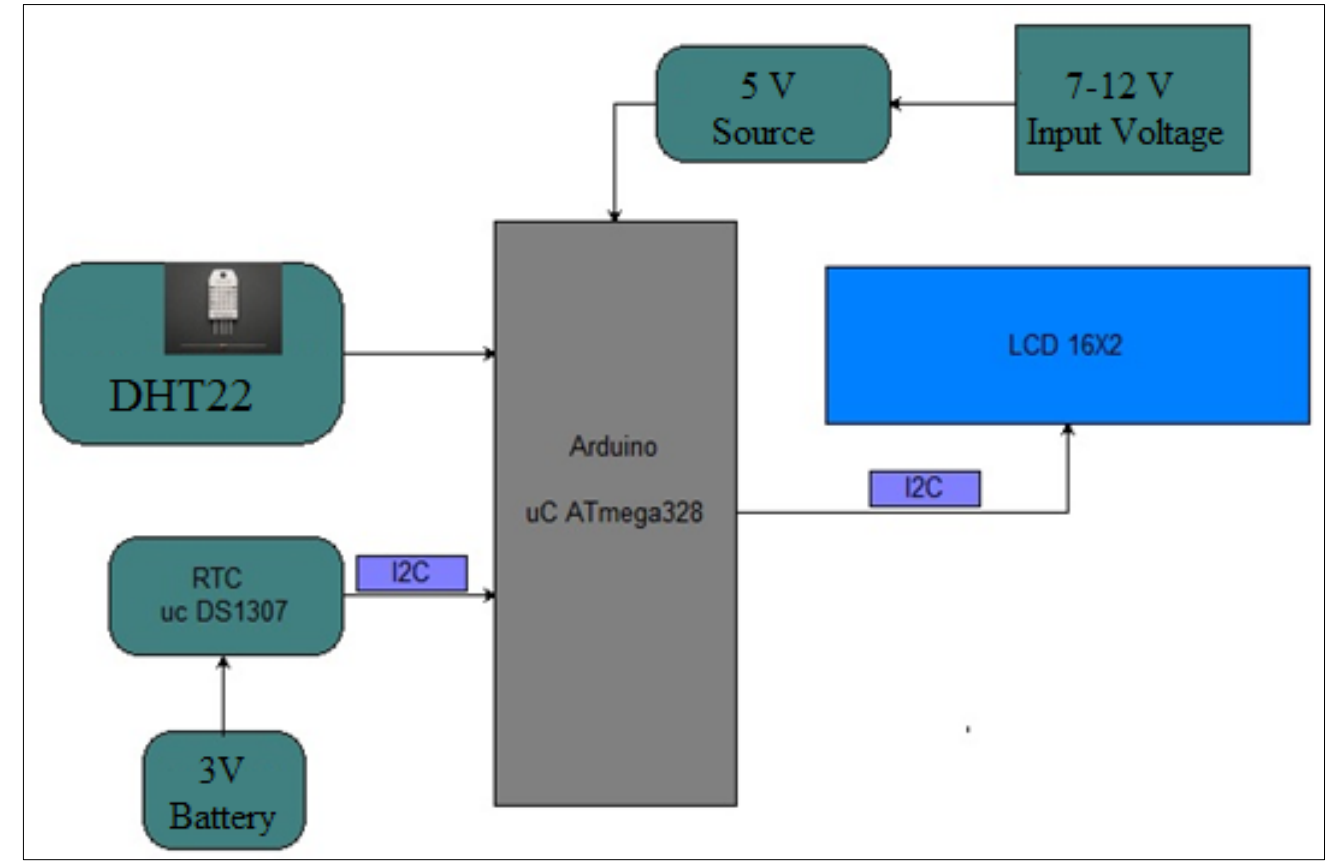

Figure 1. The block diagram of the system

Arduino block is the main block of the system. It contains development board Arduino Uno which is based on the microcontroller ATMEGA328. Arduino Uno board requires a $5 \mathrm{~V}$ supply. The input voltage block is the power supply system. This ranges from 7-12V.

The temperature and humidity sensor block contains the sensor for measuring temperature and humidity of an enclosure. The sensor used is called DHT22 .

RTC block contains Real Time Clock, used for monitoring time. It is based on DS1307 microcontroller. When powered down, RTC uses a CR2302 3V battery type.

The LCD block contains Liquide Crystal Display used to display results. It can display 16 characters on two lines. Arduino block communicate with RTC and LCD blocks, through I2C.

\section{The wiring diagram} and LCD.

Wiring diagram includes: Arduino Uno development board, DHT22 sensor, Real Time Clock (RTC)

The Real Time Clock is based on the DS1307. The internal clock has a frequency of 32,768 kHz. If power supply interruption we are using a 3V battery, type CR2302. RTC communicates with Arduino Uno via I2C.

The SDA pin of the DS1307 are connects to 4 analog pin of Arduino Uno board and SCL pin of the DS1307 is connected to 5 analog pin of Arduino Uno board. At the two lines of I2C communication are connects two pull-up resistors of $4,7 \mathrm{~K} \Omega$. 


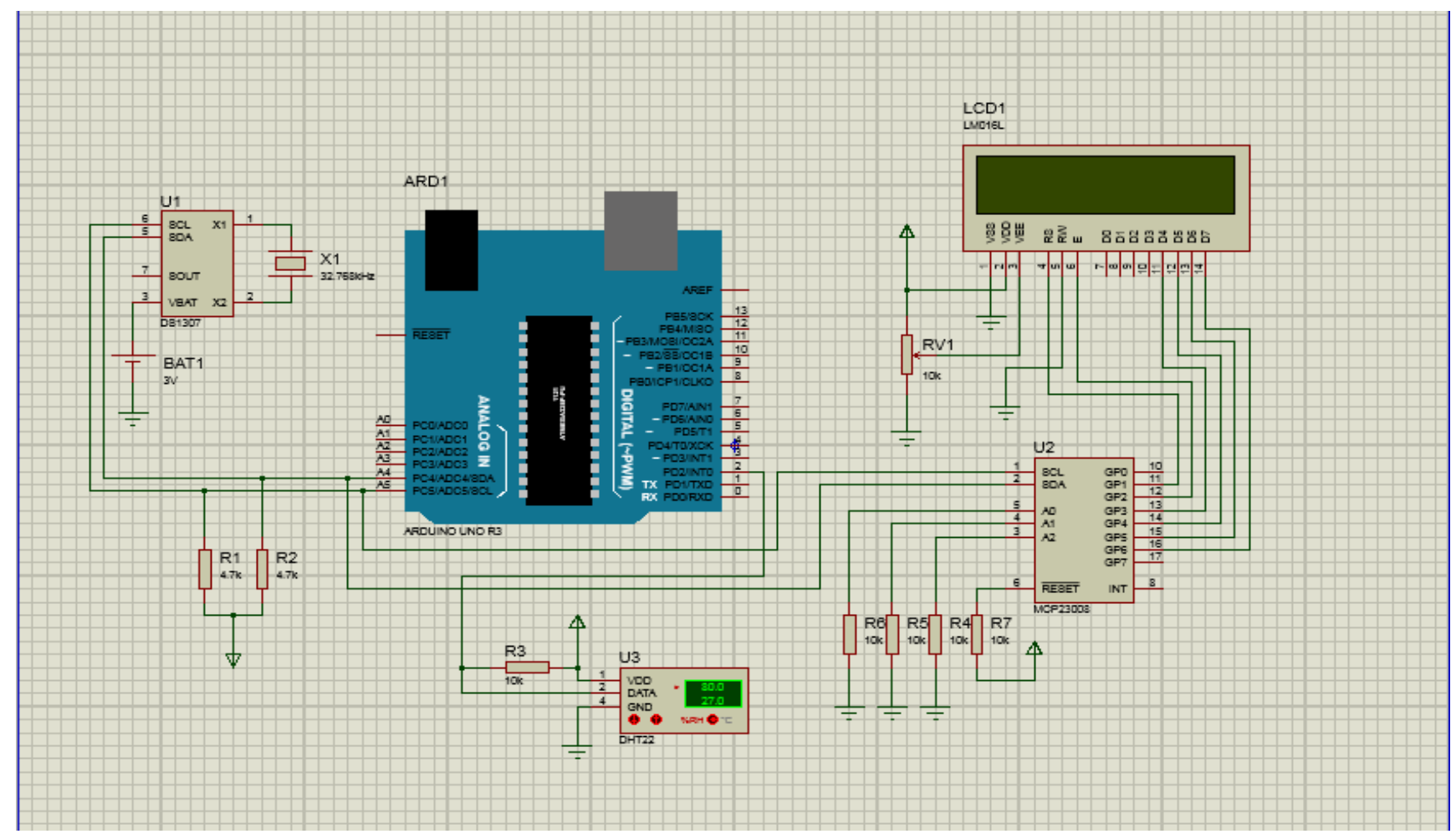

Figure 2. The wiring diagram

The DHT22 sensor measures both temperature and humidity in the room. The working temperature is $-40^{\circ} \mathrm{C} \ldots+80^{\circ} \mathrm{C}$ and the humidity range is from $0-100 \%$. The temperature has an accuracy of $0.5^{\circ} \mathrm{C}$, and the humidity, $2 \%$. Pin 2 of the sensor is connected to the 2 digital pin of the Arduino Uno board. Between 1 and 2 pins of the sensor it was connects a $10 \mathrm{~K}$ pull-up resistance. Communication between Arduino Uno board ATMEGA328 microcontroller and DHT22 sensor, is made via MaxDetect 1-wire.

The LCD used can display 16 characters on two lines. Arduino Uno board communicates with it, via I2C. Communication is made via microcontroller MCP23008. LCD contrast can be adjusted via a potentiometer.

The Arduino Uno development board is powered at $5 \mathrm{~V}$.

\section{DHT22 temperature \& humidity sensor}

DHT22 is a digital sensor consisting of a thermistor (temperature measurement) and a capacitive sensor for determining the humidity [5].

This sensor has a 4-pin :

- Pin 1 is a power pin;

- Pin 2 is data pin;

- Pin 3 is a NULL pine;

- Pin 4 is a ground pine.

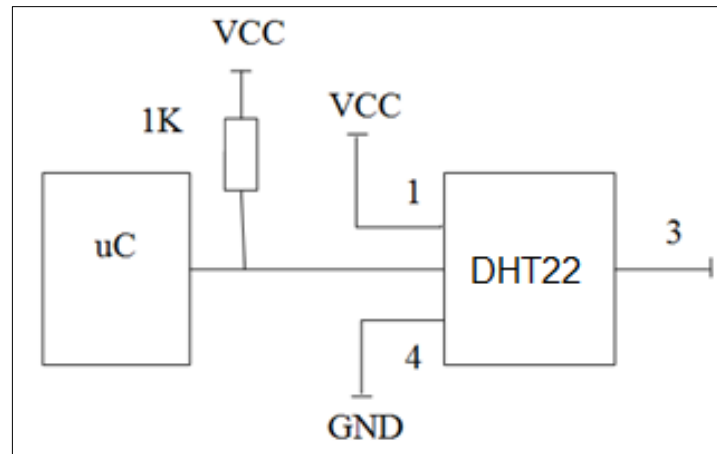

Figure 3. DHT22 temperature \& humidity sensor

The voltage supply must be between $3.3 \mathrm{~V}$ and $6 \mathrm{~V}$ (recommended $5 \mathrm{~V}$ ). Communication between Arduino Uno board ATMEGA328 microcontroller and DHT22 sensor is made through MaxDetect 1-wire. follows:

Calculation MaxDetect 1-wire: data consists of the integer part and decimal part. The formula is as

DATA $=8$ integer data bit $\mathrm{RH}+8$ decimal data bits $\mathrm{RH}+8$ data bits integer $\mathrm{T}+8$ decimal data bits $\mathrm{T}+8$ check-sum bit.

If the data is transmitted correctly, then check-sum should be: 
bits T.

Check-sum $=8$ integer data bit $\mathrm{RH}+8$ decimal data bits $\mathrm{RH}+8$ integer data bits $\mathrm{T}+8$ decimal data

Calculation example for temperature and humidity:

After connecting the sensor to Arduino Uno board, I loaded the corresponding software for measuring temperature and humidity in the room. We obtained temperature of $20.9{ }^{\circ} \mathrm{C}$ and humidity of + 57,6 RH.

The microcontroller receives 40 bits from the sensor: $16 \mathrm{RH}$ data bits, $16 \mathrm{~T}$ data bits and 8 checksum bits. Displayed data were calculated as follows:

00000010010000000000000011010001100010011

- Humidity calculation:

binar RH = $0000001001000000->$ decimal RH $=576$

$\mathrm{RH}=576 / 10=57.6 \%$

- Temperature calculation:

binar $\mathrm{T}=0000000011010001->$ decimal $\mathrm{T}=209$

$\mathrm{T}=209 / 10=20,9^{\circ} \mathrm{C}$

- Check-sum calculation:

Check-sum $=00000010+01000000+00000000+11010001=100010011$

If the highest bit of temperature is 1 , then the temperature is below 0 degrees Celsius.

\section{Conclusions}

It is the heating systems that require special attention, especially in winter, when the temperature is need to be constant, to have a desired comfort. With an acquisition boards can achieve a system that will allow monitoring temperature and humidity in a room.

Temperature and humidity measurement is essential to taking control of your environment. This functional system, in terms of hardware and software, enables us, temperature and humidity measurement of an enclosure. Also, this system monitors the time.

The accuracy of measurement system is $0.5^{\circ} \mathrm{C}$ for temperature, and respectively, $2 \%$ for moisture. Results were displayed on an LCD. This LCD can display 16 characters on two lines. They were created and displayed on LCD three symbols: a symbol for displaying temperature measuring unit (degree), a temperature icon symbol and a moisture icon symbol.

\section{References}

1. Monk, S., 30 Arduino Projects for the Evil Genius, The McGraw-Hill Companies, ISBN: 978-0-07-174134-7, (2010)

2. Schwartz, M., Programming Arduino with LabVIEW, Published by Packt Publishing Ltd., ISBN 978-1-84969822-1, (2015)

3. Amariei, C., Arduino Development Cookbook, Packt Publishing, ISBN: 978-1-78-398294-3, (2015)

4. https://www.arduino.cc

5. https://learn.adafruit.com/dht

6. http://www.npl.co.uk/upload/pdf 